\title{
Research on the Influence of Supporting Human Resource Management on Improving Employees' Sense of Happiness
}

\author{
Fang Wang \\ Xi'an Peihua University, Xi'an, Shaanxi, 710125
}

Keywords: influence; supporting human resource management; employees; sense of happiness

\begin{abstract}
In recent years, the sense of well-being of employees has been regarded as the key to improving the performance and core competitiveness of modern enterprises, and has become a focus of attention and research. This paper takes the general characteristics of human resources as the starting point, analyzes the sources of employee happiness from the perspectives of society, enterprises, and individuals, and proposes feasible measures for improving employees' happiness in a targeted manner so as to achieve a win-win situation for employees and the enterprise.
\end{abstract}

\section{Introduction}

Shaping the well-being of employees is not only one of the important goals of corporate ethical responsibility, but also an important source for enterprises to gain competitive advantage. The well-being of individuals in the workplace can effectively predict employee's emotional commitment, turnover intention and job performance, and it is also an important precursor to improving organizational performance. However, "Internet + " has promoted the upgrading and even subversion of various industrial fields. Many companies have accelerated business model innovation and organizational changes, which will inevitably bring both positive and negative impacts on employees' psychological well-being. Even employees who are happy and happy in the workplace may experience short-term loss of enthusiasm and satisfaction. Therefore, more and more companies pay more attention to the human resources management that aims to strengthen employees' happiness at work [1].

As the understanding of well-being shifts from the trait theory to constructivism, three perspectives emerged from research before work happiness: (1) Based on the vitamin model of Warr, the antecedents of work happiness were enriched in terms of work characteristics and relationship characteristics, such as autonomy. Control Opportunities, Skills Opportunities, Interpersonal Opportunities, Training and Development, External Setup Goals, Work Diversity, Environmental Definitions, Good Pay, Safe Physical Places, and Important Social Status; (2) Work Based on Bakker and Demerouti The demand-resource model explores the antecedents of work happiness in terms of work needs and work resources, such as work load, emotional labor, work area-non-work field conflicts, job autonomy, relationship support, development opportunities, and feedback; (3) Based on the work life quality model of Walton (1974), the former causes of work happiness are sought from two aspects of situational factors and individual characteristics, such as safe and healthy work environment, growth and development, relationship integration, fair salary, work flexibility, personal initiative. . However, individual traits, leadership style and other traits are relatively stable and difficult to change, which limits the practical guidance significance of the research conclusions. Although job characteristics, development opportunities, salary, etc. in contextual factors can be shaped, only these HR management practices can be implemented. Organic integration of adult resource management system can form a unique competitive advantage. Therefore, it is very necessary to explore the impact of human resource management system on job well-being [2]. 


\section{Enhancing the Happiness of Employees in Enterprises is an Inevitable Choice for Enterprise Development}

At present, China is undergoing a major historical period of economic restructuring. Increasing market competition, the pressure for change brought about by rapid development, the urgent pursuit of interests, and the inner desire for personal growth all make employees face enormous challenges and psychological impact. . The "Happy Planet Index" of the "New Economic Fund" of the United Kingdom ranks all countries as the world's most authoritative survey on the happiness index. The highest green color is concentrated in the European region; the worst red color is in the poverty-stricken areas of Africa; Asia is mostly in the yellow area, including China, all at a medium level. In 2004, the China National Human Resource Development Network conducted a nationwide survey on the "Working Well-being Index" and found that the overall "job happiness index" of Chinese employees was 2.57, which was in the middle-lower state, and 64\% of the respondents were working happy. The index score is not high. In 2011, China's total GDP exceeded Japan and became the world's second largest economy. In the past three years, the well-being of Chinese employees has not grown with GDP, but has decreased. Chinese companies often neglect employee management while trying to expand rapidly and chase high returns. Many managers often complain that behind the company's continuous increase in employee salaries and increase in labor costs, employees' satisfaction is low, professionalism declines, and turnover rate increases [3].

Employee well-being is the source of motivation for the development of the company. Employee well-being is a kind of measurable and developable positive mental state. It has a positive effect on job performance, job satisfaction and organizational commitment. Improving employee happiness is an inevitable choice for companies to improve their performance and gain development. First of all, improving the well-being of employees in enterprises helps improve job performance. Wright, Cropanzano's study confirmed that psychological well-being is conducive to improving the dual benefits of employers and employees and promoting organizational productivity. Chen Liang and Sun Qian found that subjective work well-being and peripheral performance have a mutual influence relationship. Feng Xiao found that happy employees are also high-performance employees. They have positive and positive emotions. They make them more creative and adaptable in their work, and are more likely to be praised by their superiors and colleagues, thus urging employees to become more actively work hard to improve work performance. Second, improving employees' well-being can help improve job satisfaction. Hofmann \& Tetrick found that happiness can be directly translated into the health costs of employees, which is conducive to maintaining a good physical and mental health status of the employees. This state is the source of job satisfaction. The meta-analysis of Bowling et al. shows that positive and negative emotions have positive and negative effects on job satisfaction, salary satisfaction, leadership satisfaction, colleague satisfaction, and promotion satisfaction, respectively. Research confirms that job satisfaction and employee well-being have certain emotional roots. Emotional and cognitive components of employee well-being have predictability for job satisfaction. Finally, improving employee well-being helps increase organizational commitment. HueyMing Tzeng's study found that the higher the employee's well-being, the lower the employee's turnover tendency. Pan Liping found that subjective well-being of corporate knowledge workers is positively related to organizational commitment, and subjective well-being has a certain influence on organizational commitment. Therefore, employees with a sense of well-being can better cope with difficulties and crises, seize opportunities reduce turnover and burnout.

In short, employees' happiness is a reflection of employees' positive mentality, providing human resources support for enterprises' access to core competitiveness and sustainable development, and has become a source of power for the development of enterprises [4].

\section{Related Research on Supporting Human Resources Management and Happiness}

Although the happiness-oriented human resource management practices are more focused on 
how to motivate employees' job well-being, not all human resource management practices can individually promote employees' well-being. Guest refined the happiness-oriented human resource management practices, including investment in employees (such as recruitment selection, training development, guidance and professional support), and providing participatory work (such as autonomy and challenging job design, information provision and (feedback, full use of skills), positive relationships, and physical environment (eg health and safety priorities, equal opportunities, diversified management, zero tolerance for abusiveness and infringement, flexible social interaction, fair collective rewards/high basic pay, employment security), advocacy mechanisms (such as extensive bilateral communication, employee surveys, collective representation), organizational support (participation/support management, participation atmosphere and practice, flexible family-friendly work arrangements, and developmental performance management). However, these individual or decentralized human resource management practices have only a limited impact on job well-being. For example, work autonomy can both stress employees and promote job satisfaction. Supportive human resources management was initially proposed by Allen et al. and is an organic integration of several happiness-oriented human resource management practices. It extends from three elements of career development, welfare, and training to employee participation, fair rewards, growth and training, superior support, and employment security. And so on, these practices are highly complementary and consistent and can play a coordinating role.

There are realization theory and enjoyment theory in work happiness. Among them, implementation theory pays attention to the meaning and self-realization of life, while enjoyment theory focuses on the acquisition of happiness and the avoidance of pain. Therefore, integrating the view of realizationism and hedonism, work happiness is a result state, and its production mainly depends on two key elements. The first element is the positive emotional experience, which can expand the body, intelligence and social Resources; the second element is the overall sense of purpose, which gives direction and meaning to human actions. On the one hand, supportive human resources management can enable employees to obtain "economic returns" and "psychological rewards" and enrich their work resources. Work resources from supportive human resources management can not only affect job well-being. For example, providing leadership skills training and nurturing iconic advantages at work can effectively enhance employees' happiness, and can also improve employee happiness by changing employee perceptions of role blurring and control. The impact of well-being, such as the work design of employee participation, can reduce employee burnout at work and even bring joy to the work itself. On the other hand, there is a ripple effect in the sense of well-being among members of the group. Collective work well-being is based on the individual's perception of the collective as a whole and is driven by factors such as organizational climate. The group is composed of several individuals who are members. Individuals' positive emotions can infect the surrounding people. Individuals with a high sense of work happiness gather together and form overall collective work happiness. Therefore, supportive human resources management can not only promote the individual work well-being of employees, but also can promote the group's collective work happiness.

\section{Research on the Strategy of Supporting Human Resources Management to Improve Employee Happiness}

The implementation of supportive human resources management by managers must not only provide tangible "acquisition" but also create a sense of ownership of the owners in order to maintain the collective happiness of the collective. Work happiness is neither static nor rapid, and requires tangible investment and intangible investment. Therefore, the implementation of supportive human resources management can not be empty shouting slogans, but to really benefit the majority of employees, real tangible gain will inevitably bring happiness in collective work. Of course, with the improvement of happiness in collective work, the tangible investment in maintaining happiness will also rise to a certain extent. However, managers provide substantial and tangible input through supportive human resources management, and pass the company's care to all employees. The employees will treat the company as their "home" psychologically, and gradually form a "home" 
culture atmosphere. . Only the "home" culture infiltrates the psychological feelings of employees as a result of the spring rain, so that employees have a sense of belonging and a sense of accomplishment. Only in this way can they maintain the sense of collective happiness in the collective work [5].

Supportive human resources management can only promote the individual's sense of well-being if they are transformed into employees' sense of gain. For individuals, sense of gain is an important precondition for working well-being. Working well-being is an important goal to obtain, and the effect of sense of acquisition is even more significant than the actual effect on individual job well-being. Individual work happiness does not come out of thin air. It needs more sense of gain to transform. The sense of gain will not come from the sky, it comes from the implementation of the company's supportive human resources management. Of course, the "feeling of gain" includes the process of constructing the meanings of "give" and "get", and focuses on the subjective interpretation of the individual's tangible giving, covering "the feeling of belonging", "the sense of honor" and "the sense of achievement". For enterprises, it is necessary to change the eagerness and quick-motivation mentality of "giving" that is achieved through the implementation of supportive human resources management. It is necessary to pay more attention to the subjective perception of "acquisition" by employees. In particular, organizational identity and self-efficacy are important mediators in employee happiness management and should be valued by the organization. On the one hand, organizational recognition is the sense of belonging "respected" and "respected" formed by employees on the basis of real access, which can enhance the individual's sense of well-being. In the era of human capital, the future organization is the platform of business partners. Employees are regarded as partners. Their sense of well-being is rooted in the recognition of corporate culture, values, and platform businesses. Therefore, managers can implement supportive human resources management in a targeted manner to enhance organizational identification of employees, such as encouraging employees to participate in management, constructing a warm organizational culture, and paying attention to the realization of employees' own values. On the other hand, self-efficacy is one of the performance-enhancing performances of employees after their acquisition, which can awaken individual job well-being. Organizations can carry out targeted and supportive human resource management to awaken employees' sense of self-efficacy. For example, in the recruitment of employees, they should pay attention to whether candidates have successful working experience in the past, and pay attention to training employees' self-confidence in the training of new employees. In the management, timely application of positive feedback, social recognition and psychological counseling are used to enhance the personal happiness of employees.

\section{Conclusion}

In summary, with the continuous development of China's social economy, the theme of management is also changing quietly. From the people-oriented, harmonious society to the promotion of happiness index, more and more companies began to regard "creating a happy organization" as an important goal of enterprise development. This requires companies to re-examine corporate management from the perspective of happiness, so that employees in the realization of value and experience of happiness, while creating greater benefits for the enterprise, to achieve a win-win situation for both companies and individuals. Introducing the idea of happiness in the research of theory and practice has provided new research ideas and thinking methods for enterprise management. It has certain theoretical and practical significance for the Chinese enterprises to realize healthy development and build a harmonious society in the transition period and deserves further research and exploration.

\section{References}

[1] Chen Chunhua, Song Yixiao, Cao Zhoutao. The internal mechanisms of organizational support resources affecting employees' well-being: Case studies based on the vision of Rui Technology [J]. Journal of Management, 2014, (2): 206-214. 
[2] Chen Zhixia, Chen Chuanhong. The Impact of Organizational Support and Supportive Human Resource Management on the Performance of Employees [J]. Mathematical Statistics and Management, 2010,(4): 719-727.

[3] Du Yong, Li Nanang, Long Lirong. Research on High Performance Work System and Employee Well-being Based on Self-efficacy Mediating Role [J]. Chinese Journal of Management, 2014, (2): 215-221,243.

[4] Feng Dongdong, Lu Changqin, Xiao Ailing. Relationship between job insecurity, well-being, and performance: The role of self-efficacy [J]. Acta Psychologica Sinica, 2008, (4): 448-455.

[5] Guo Jing, Zhou Xiaohua, Lin Guowen, et al. Job requirements - Application of control models in Chinese industrial workers: Response surface analysis and curve relationships [J]. Managerial World, 2014, (11): 80-94. 